\title{
A relação entre pintura e natureza em Alberti
}

Fabrício Behrmann Mineo

\section{Resumo:}

No tratado de Alberti sobre pintura, a ideia de natureza desempenha um papel fundamental. Para Alberti, o pintor deve aprender seu ofício através da observação da natureza. Neste artigo, apresentaremos alguns dos principais movimentos dos dois primeiros livros do Da pintura, tendo em vista a relação entre pintura e natureza. Inicialmente, abordaremos os rudimentos da pintura, com ênfase na perspectiva e considerando a concepção de pintura como janela, desenvolvida por Alberti. Em seguida, trataremos das três partes da pintura e suas relações com a natureza. Nesse ponto, a composição (uma das partes da pintura) aponta para uma noção de beleza que, de certo modo, excede a natureza.

Palavras-chave: Pintura - Natureza - Perspectiva - Composição - Beleza 
A relação entre pintura e natureza em Alberti

\section{Introdução}

Em I435, Leon Battista Alberti conclui a redação, em latim, do primeiro tratado sobre pintura que chegou até nós, o Da pintura. Um ano mais tarde é publicada uma versão vernacular do texto, ${ }^{\mathrm{I}}$ em que se baseia a tradução utilizada como referência para este artigo. A obra busca alçar a pintura à condição de arte liberal e constituí-la como objeto de doutrina, sistematizando-a e instruindo os artistas que pretendem dominá-la. Alberti divide seu tratado em três livros tratando, primeiramente, dos rudimentos da pintura; em seguida, da divisão dessa arte em três partes; e, por fim, das questões que dizem respeito ao ofício e à conduta do pintor. Em sua concepção de pintura, salta aos olhos a proeminente relação entre pintura e natureza. Desde as primeiras linhas, o autor afirma que mesmo os princípios da pintura são extraídos da natureza. Além disso, em várias passagens ao longo dos três livros a relação entre pintura e natureza é continuamente lembrada, indicando que o artífice que pretende alcançar a maestria na pintura deve aprender observando a natureza. Sendo assim, poderíamos perguntar: qual a relação entre pintura e natureza no Da pintura?

Neste trabalho, indicaremos como essa relação aparece ao longo do texto, em especial, nos livros Primeiro e Segundo. Desse modo, de início, buscaremos mostrar como o conceito de pintura do autor - da pintura como janela - fornece uma indicação para compreendermos essa relação. Nesse ponto, trataremos também dos rudimentos da pintura, percorrendo alguns dos principais momentos do Livro Primeiro. Em segundo lugar, exporemos a divisão da pintura em três partes: circunscrição, recepção de luzes e composição (alterando ligeiramente a ordem de exposição do Dapintura). Utilizaremos como fio condutor a relação entre pintura e natureza, tentando explicitar a importância dessa vinculação na doutrina e nos ensinamentos expostos no tratado.

\section{Primeira parte}

O Da pintura se apresenta como um conjunto de ensinamentos e doutrinas que busca instruir aqueles que pretendem se iniciar no ofício da pintura. E isso é algo sem precedentes, nenhum outro tratado de pintura sobreviveu ao tempo.

I Sobre as questões relativas às datas de redação, bem como ao caráter "bilíngue" do texto, cf. GRAYSON I999, pp. 46-5I. 
O tratado de Alberti "é o primeiro, na literatura artística, a constituir a pintura como objeto de teoria e doutrina sistematizadas" (KOSSOVITCH I999, p. 9). Trata-se de um texto complexo, no qual diversos tipos de saberes e discursos se intercalam. Geometria, ótica, retórica e história das artes fornecem uma base extremamente diversificada e ampla. De acordo com Kossovitch, "Alberti monta seu discurso com geometria e retórica (e poética), instruindo aprendiz distinto do dos autores precedentes, pois familiarizado com artes liberais" (id. ibid., p. 9). A retórica fornece uma importante base para o discurso albertiano, sistematizando a pintura e contribuindo para a sua divisão sistemática, como veremos adiante ao discorrer sobre as três partes da pintura. No entanto, a transposição de conceitos não é feita de forma mecânica, a retórica não recobre completamente a pintura, que tem sua independência assegurada. O que ocorre é a transposição e importação de conceitos das artes liberais para a pintura, por isso aquele que pretende tornar-se pintor deve ser versado em diferentes áreas do saber. Essa "dimensão letrada" desempenha um papel crucial na constituição da pintura como objeto de doutrina sistematizada.

Além disso, no Da pintura o discurso preceptivo, que trata de fundamentos e aspectos técnicos, dá lugar ao discurso epidítico, ao elogio ou censura de certos modos de proceder, buscando incentivar ou desestimular determinadas práticas. A partir disso, poderíamos ser induzidos a pensar que a pintura é então arte para uns poucos iniciados - destinada à apreciação de um seleto grupo de eruditos. Nada mais enganoso. Embora a redação do tratado possa ter tido como um de seus principais objetivos a elevação da pintura à condição de arte liberal - e, assim, a obra foi composta primeiramente em latim, a língua culta -, não se pode ignorar a preocupação humanista de Alberti em vertê-la para a linguagem vulgar, possivelmente, a fim de contribuir com seus amigos artistas que não liam em latim (GRAYSON I999, p. 50). Além disso, ainda que a pintura exija do artífice certo grau de instrução, para Alberti, o resultado do trabalho do artífice deve ser agradável a todos, tanto a doutos quanto a leigos. A pintura bem executada pode ser admirada pelo público em geral, sem distinção (ALBERTI I999, p. I50, \$ 62). ${ }^{2}$

Nesse sentido, é importante que o pintor seja capaz de representar as coisas vistas de maneira precisa e acurada. Aqui chegamos ao cerne do nosso problema: a relação entre pintura e natureza. ${ }^{3}$ Além das aproximações da pintura

2 Nas citações do Da pintura, além da referência à página forneceremos o número do parágrafo.

3 Ao falar dos objetivos de Alberti na concepção de seu tratado sobre pintura, Grayson afirma o seguinte: "para recriar ex novo à arte da pintura, ele se baseia, de um lado, na experiência própria de 
A relação entre pintura e natureza em Alberti

com outras áreas do conhecimento (retórica, ótica e geometria), com outras artes, há ainda uma relação mais fundamental, que parece ter precedência. Um pintor competente deve, antes de tudo, ser capaz de imitar a natureza, de representar os objetos animados e inanimados. Conforme as concepções apresentadas no Da pintura, "de artesão, o pintor passa a ser um culto imitador e recriador da natureza" (GRAYSON I999, p. 52). Em várias passagens do Da pintura, o autor insiste que o pintor incipiente precisa observar e investigar a natureza com o intuito de aprender os princípios do seu ofício. Pintura e natureza estão intrinsecamente ligadas em razão da própria definição de pintura fornecida pelo autor.

Segundo Alberti, uma pintura deve ser como uma janela ${ }^{4}$ através da qual é possível observar a cena representada. A superfície da pintura é como um vidro translúcido pelo qual o observador, posicionado a certa distância, pode ver os objetos pintados como se tivessem profundidade (cf. ALBERTI I999, p. 87, ( 2 ).

O ofício do pintor é este: descrever com linhas e pintar com cores, em qualquer quadro ou parede que se lhe apresente, superfícies vistas de qualquer corpo, os quais, a uma certa distância e em uma certa posição do centro, parecem estar em relevo e ter muita semelhança com os corpos (id. ibid., p. I37, \$ 52 ).

Para isso, o pintor deve ser capaz de representar as coisas vistas e de imitar a natureza; antes de tudo, o pintor precisa ser um observador da natureza, aprendendo com ela o que é essencial para sua arte. Com isso, é possível afirmar que a concepção de natureza da qual Alberti se ocupa está relacionada com a percepção sensorial, o que interessa ao pintor é o mundo visível e a natureza da visão - ou "uma imagem ótica presente nos seus olhos" (PANOFSKY I960, p. I69). Assim, a partir da observação da natureza o pintor aprende os fundamentos de seu ofício. "Por isso, diremos de que modo alguém pode tornar-se entendido nessa arte. Não se tenha a menor dúvida de que a cabeça e o princípio desta arte, bem como todas as etapas para se tornar mestre nela, devem ser buscados na natureza” (ALBERTI I999, p. I4I, \$ 55). Podemos afirmar que a concepção da pintura como janela condiciona os passos sub-

pintor e observador da natureza e, de outro, no estudo de arte, história, literatura e matemática. [...] Além do mais, era um homem culto que queria e podia entender a história e a finalidade da arte e concebê-la como atividade criadora e expressão interpretativa das relações entre o homem e a natureza" (I999, p. 53).

4 Sobre a "visualização da pintura como uma janela", cf. GRAYSON I999, pp. 59-60. 
sequentes para adquirir a maestria nessa arte. A imitação da natureza como objetivo da pintura culmina na observação como princípio; o pintor precisa ser capaz de extrair da natureza os fundamentos da sua arte. De acordo com Panofsky, "comparar uma pintura com uma janela é atribuir ao artista, ou dele exigir, uma abordagem visual e direta da realidade" (Ig6o, p. I69).

A construção da perspectiva aparece como um dos elementos decisivos desse conceito de pintura. "A analogia da janela de Alberti define a pintura não apenas como o registro de uma experiência visual direta, mas também, mais especificamente, como uma representação 'em perspectiva'" (PANOFSKY I960, p. I72). A pintura como janela só pode ser alcançada se a técnica do pintor for capaz de representar o modo como os objetos são percebidos pela visão. Segundo Grayson, trata-se de oferecer uma solução a um dos problemas primordiais da pintura, a saber, o de "como representar na superfície plana o espaço e os objetos tridimensionais" (I999, p. 56). Nesse sentido, a técnica da perspectiva é a responsável por fazer com que algo pintado em uma superfície bidimensional apareça ao observador como tridimensional. "Um espaço pictórico poderá ser definido como uma área aparentemente tridimensional, [...] que parece estender-se indefinidamente, sem ser necessário que seja infinitamente, para além da superfície pintada objetivamente bidimensional" (PANOFSKY I960, p. I68). A profundidade da pintura deve ser produzida, sobretudo, com o uso de técnicas de desenho capazes de dar profundidade aos objetos representados - em suma, perspectiva. Por esse motivo, o conhecimento e o domínio da geometria é de grande importância. De acordo com Alberti, é preciso, antes de qualquer coisa, que o pintor saiba geometria (ALBERTI I999, p. I38, \$ 53). Não é por outra razão que o Livro Primeiro se inicia tratando justamente de geometria, um dos rudimentos da pintura.

Uma doutrina sistemática da pintura deve partir dos "primeiros princípios da natureza”. Ora, as coisas naturais em sua relação com o sentido da visão são, antes de tudo, percebidas segundo uma relação geométrica. Em primeiro lugar, é preciso tratar de geometria, não de uma geometria pura, mas de uma geometria do espaço visual. Logo de início, Alberti deixa claro que não fala como geômetra para outros geômetras, sua exposição é, sobretudo, de pintor para pintores. Isso implica que o seu tratamento da geometria está comprometido e, de certa maneira, subordinado à visão. Sendo assim, o pintor se serve de uma "Minerva mais gorda", pois o objetivo do pintor é utilizar a geometria para bem representar as coisas naturais. Por isso, uma das primeiras definições de Alberti é a de sinal: "chamo aqui sinal qualquer coisa que esteja na superfície, de modo que o olho possa vê-la. As coisas que não podemos ver, ninguém negará que elas não pertencem ao pintor. $O$ pintor só se 
esforça por representar aquilo que se vê" (id. ibid., p. 76, § 2). Desse modo, a pintura - como artifício, como técnica - precisa de uma base geométrica para imitar a natureza; mais especificamente, para representar os objetos tal como são apreendidos pela visão (uma representação em perspectiva). Com isso, a pintura torna-se "uma janela através da qual podemos contemplar uma parte do mundo visível" (PANOFSKY ig6o, p. I68).

Após algumas definições básicas (como ponto, linha, reta, curva), o texto chega à importante noção de superfície, isto é, "a parte extrema de um corpo que é conhecida, não por sua profundidade, mas tão somente por seu comprimento, largura e, ainda, por suas qualidades" (ALBERTI I999, p. 76, § 2). Essa noção é de extrema importância, pois é o que há de mais elementar na pintura, como veremos na segunda parte. Até agora, temos falado de superfície para nos referirmos à superfície da pintura, no entanto, é importante não confundir as duas. A superfície tratada aqui é a superfície das coisas vistas, sua parte externa visível, com suas qualidades.

Enquanto trata de geometria, o texto de Alberti vai sensivelmente se deslocando para questões relativas à ótica. Cada vez mais o espaço geométrico dá lugar ao "espaço visual" e, assim, o texto começa a se ocupar de noções ligadas à visão. Segundo Kossovitch, "a geometria de base euclidiana, exposta nas definições elementares e operante na análise da perspectiva, é, todavia, superada por noções tiradas da óptica, porquanto é a visão, no texto, a interessada" (I999, p. I3). Inicialmente, é apresentada a noção de raios visuais, que nada mais são que algumas linhas muito tênues saindo das coisas em direção ao olho (a sede do sentido da visão), formando dessa maneira uma imagem. Os raios se diferenciam em três tipos: os extremos, os médios e o cêntrico. O modo de organização desses raios visuais conduz à formulação da noção de ótica mais importante do Da pintura, a pirâmide visual.

"Entre o olho e a superfície se constrói a pirâmide visual" (KOSSOVITCH I999, p. I4). Os raios visuais extremos, ou extrínsecos, são aqueles que produzem os lados da pirâmide e envolvem a superfície vista. Nas palavras de Alberti, "a base dessa pirâmide é uma superfície que se vê. Os lados da pirâmide são aqueles raios que chamei extrínsecos. O vértice, isto é, a ponta da pirâmide, está dentro do olho, onde está o ângulo das quantidades" (I999, p. $82, \$ 7)$. Assim, a pirâmide se forma nessa relação entre a superfície observada e o olho do observador, sendo que o vértice da pirâmide está no olho.

A pintura (como janela) nada mais é do que uma intersecção dessa pirâmide visual. "Não será, pois, a pintura outra coisa que a intersecção da pirâmide visual representada com arte por linhas e cores numa dada superfície, de acordo com uma certa distância e posição do centro e o estabelecimento de luzes" (ALBERTI 
I999, p. 88, § I2). Portanto, a superfície da pintura é uma intersecção da pirâmide visual, que se interpõe entre o olho do observador e a base da pirâmide. Em certo sentido, a profundidade artificial proporcionada pela pintura, com sua superfície bidimensional, cria uma espécie de "prolongamento ilusório" da pirâmide visual. Para tanto, a distância do observador e a posição em relação do centro são determinantes na elaboração pictórica. De acordo com Kossovitch, "a distância e o raio cêntrico definem a construção perspectivista" (I999, p. I4). Desse modo, a consideração da pirâmide visual e dos raios visuais conduz ao tema da perspectiva na pintura. A perspectiva natural (da ótica) engendra a reflexão técnica acerca da perspectiva artificial (da pintura). Sendo que esta última - como técnica e artifício - é um dos meios de que o pintor dispõe para realizar seu objetivo.

$\mathrm{Na}$ construção da perspectiva é interessante notar que a medida do espaço pictórico é fornecida pelo próprio homem. Nesse sentido, Alberti vale-se da afirmação de Protágoras, de que o homem é a medida das coisas, sendo que na pintura isso se dá de forma literal (ALBERTI I999, p. 93, § I8). Na aplicação prática, o homem-medida é utilizado para dividir a superfície da pintura (o quadrângulo traçado pelo pintor) em braços, sendo que a altura de um homem é equivalente a três braços. De acordo com Kossovitch, na pintura o homem aparece "como unidade de mensuração: o braço dá as unidades da construção perspectivista, enquanto a cabeça (substituindo o pé vitruviano, por ser este igual em medida, mas superior em dignidade) opera como unidade nas proporções do corpo humano" (I999, p. I7). De acordo com $\mathrm{Pa}$ nofsky (I96o, p. 52), essa singular preocupação com as proporções humanas nas artes figurativas, introduzida por Alberti, poderia ser chamada de "antropometria estética”. Desse modo, a construção da perspectiva tem no braço sua medida fundamental (ALBERTI I999, p. 94, \$ I9). Somente com uma medida que seja interna à pintura, o artista pode construir a perspectiva, produzindo, assim, o tão almejado efeito de janela. É a medida do braço que vai indicar ao pintor, pela divisão do quadrângulo de ângulos retos (quer dizer, a superfície da pintura), a proporção das coisas pintadas conforme a distância e a posição em relação ao ponto cêntrico.

Inicialmente, a técnica da perspectiva deve ser aprendida pelo pintor através da observação da própria natureza. A natureza ensina que um homem posicionado ao fundo deve ser pintado menor do que outro que está à frente.

Daí vem que os homens pintados, colocados no último braço quadrado da pintura, são menores que os outros. Que as coisas sejam assim, a própria natureza no-lo demonstra. Vemos nos templos que as cabeças de quase todos os homens 
A relação entre pintura e natureza em Alberti

estão em um mesmo nível, mas os pés dos mais afastados correspondem aos joelhos dos mais próximos (ALBERTI 1999, pp. 97-98, \$20).

A imitação da natureza necessita, portanto, de uma construção precisa da perspectiva, a fim de que as relações e proporções dos objetos no espaço visual possam ser representadas de maneira adequada no espaço pictórico. Os objetos da pintura precisam ser semelhantes às coisas verdadeiras. Sobre essa questão, Alberti afirma: "saiba-se bem que nenhuma coisa pintada jamais poderá ser semelhante às coisas verdadeiras, se não houver uma determinada distância para vê-la" (ibid., p. 96, § I9). Nesse sentido, o efeito de perspectiva depende da distância que o pintor determina para que a obra seja apreciada. Quando o observador se coloca na posição correta pode ver a cena pintada em perspectiva.

Além da distância do observador, o ponto cêntrico desempenha um papel crucial. Trata-se de um ponto posicionado na altura dos olhos do observador, portanto, condicionado pelo "ponto de vista". Esse ponto, posicionado na "linha do horizonte" (linha paralela à base do quadrângulo), nada mais é que um "ponto de fuga", para o qual convergem todas as "linhas paralelas" da pintura. Sendo assim, é o ponto em que as "linhas paralelas" (por exemplo, as linhas do pavimento) se tocam. Segundo Panofsky, esse ponto cêntrico simboliza visualmente a infinidade do espaço: ${ }^{5}$

A infinidade é implicada - ou, antes, visualmente simbolizada - pelo fato de qualquer conjunto de linhas objetivamente paralelas, independentemente de sua situação e direção, convergir para um único "ponto de fuga", que assim representa, no sentido mais literal do termo, um ponto onde as paralelas se encontram, quer dizer, um ponto situado no infinito (I96o, p. I75).

O construto perspectivista depende, além disso, da divisão do espaço pictórico. Entra em cena o nosso "homem-medida". Isso porque a divisão do quadrângulo em braços - tanto de sua base como de sua altura - junto com a indicação da distância do observador determinam as medidas dos braços quadrados no pavimento da pintura. Pois, da mesma forma que as linhas da divisão de base do quadrângulo convergem para o ponto cêntrico, outras linhas - partindo da mesma divisão de base - devem ser traçadas até o "ponto de vista" (que deve estar

5 De acordo com Panofsky, as ideias de continuidade e infinidade eram pressupostas e exemplificadas pela representação em perspectiva (cf. I960, pp. I7I-72), ainda que não estivessem plenamente desenvolvidas do ponto de vista filosófico e cosmológico. 
na mesma altura do ponto cêntrico e, preferencialmente, fora do quadrângulo), formando intersecções entre essas linhas. Os braços quadrados da pintura formam uma espécie de "tabuleiro de xadrez" em perspectiva, que permite ao pintor saber a proporção e o tamanho dos objetos que serão pintados. ${ }^{6}$

De modo geral, esses são os principais tópicos do Livro Primeiro, em que Alberti trata dos rudimentos da pintura (ALBERTI I999, p. 99, § 23). Terminada a exposição dos fundamentos, podemos, então, passar aos principais temas do Livro Segundo. Buscaremos mostrar a relação entre pintura e natureza enquanto tratamos da divisão em três partes, proposta por Alberti.

\section{Segunda parte}

Os primeiros parágrafos ( $\$ \S 25-29$ ) do Livro Segundo são tecidos de acordo com o gênero epidítico. Esse encômio consiste em ressaltar a glória e a posição honrosa da pintura, discursando sobre a pintura na Antiguidade e destacando o prazer e o deleite que ela proporciona aos homens. Após o elogio da pintura, Alberti apresenta as três partes da pintura. Para ele, as três partes são retiradas diretamente da natureza, não se trata, portanto, de uma divisão arbitrária. "Divide-se a pintura em três partes: essa divisão nós a tiramos da própria natureza. Como a pintura se dedica a representar as coisas vistas, procuremos notar como são vistas as coisas" (id. ibid., p. I08, § 30). Um descolamento dessa relação leva o pintor ao fracasso, já que não seria capaz de realizar seu ofício de modo satisfatório, sem a observação da natureza o artífice é levado ao erro. Desse modo, o pintor não pode desenvolver sua técnica sem que tenha contato com as coisas naturais, tais como aparecem ao sentido da visão.

As três partes da pintura são circunscrição, composição e recepção de luzes. Cada uma dessas partes sendo aprendida a partir da observação da natureza. ${ }^{7}$ De certo modo, a pintura é afirmada como "configuração da natureza" (KOSSOVITCH I999, p. 2I).

6 Sobre a construção da perspectiva, ver as imagens em PANOFSKY I96o, p. I74.

7 Embora Alberti afirme claramente que as partes da pintura são retiradas da própria natureza, não podemos deixar de notar que a divisão proposta pelo autor tem uma aproximação com as partes da retórica. Segundo Panofsky, "a Alberti se deve igualmente a tentativa de adaptar à profissão do pintor as categorias da retórica clássica: a invenção, a disposição (tornada circonscriptione e compositione e, cerca de cem anos mais tarde, substituída por disegno), e a expressão (tornada receptione de lume e cerca de cem anos mais tarde substituída por colorito)" (I960, p. 50). No entanto, um tratamento adequado da importante contribuição da retórica para a redação do Da pintura infelizmente foge às nossas capacidades e ao nosso objetivo. 
A relação entre pintura e natureza em Alberti

Em primeiro lugar, ao ver uma coisa, dizemos que ela ocupa um lugar. Neste ponto, o pintor, descrevendo um espaço, dirá que percorrer uma orla com linha é uma circunscrição. Logo em seguida, olhando esse espaço, fica sabendo que muitas superfícies desse corpo visto convêm entre si, e então o artista, marcando-as em seus lugares, dirá que está fazendo uma composição. Por último, discernimos mais distintamente as cores e as qualidades das superfícies e, como toda diferença se origina da luz, com propriedade podemos chamar sua representação de recepção de luzes (ALBERTI I999, p. I08, \$30).

A primeira parte se refere ao lugar que a coisa ocupa; ou, ainda, trata-se da descrição, com linhas, das orlas das coisas vistas, de suas superfícies, é o primado do desenho em relação às outras partes. Na segunda parte, é importante notar certa conveniência das superfícies entre si; poderíamos dizer que, a princípio, trata-se da proporção, da justa medida entre as superfícies que juntas compõem a pintura. Por fim, as cores e os efeitos provocados pela incidência de luz, em suma, luz e sombra. As três partes da pintura originam preceitos técnicos, de modo que cada uma delas recobre um campo do fazer, um aspecto da técnica pictórica que deve ser dominada pelo pintor (cf. KOSSOVITCH i999, p. 2I). A seguir, trataremos das partes da pintura em sua relação com a natureza.

A primeira parte da pintura é a circunscrição, ou seja, a descrição com linhas do lugar ocupado pelos objetos representados na superfície da pintura. "A circunscrição nada mais é que o delineamento da orla" (ALBERTI I999, p. IO9, \$ 3I); ou ainda, "a circunscrição nada mais é que um certo processo de assinalar os contornos das superfícies" (id. ibid., p. II2, § 33). Sendo assim, circunscrição é delineamento das coisas vistas pelo pintor; esse é o primeiro passo para a representação pictórica dos objetos naturais. Segundo Kossovitch, circunscrição é desenho (I999, p. 2I). Do ponto de vista técnico, a principal função da circunscrição é a fixação da orla dos objetos que serão representados pelo pintor. Inicialmente, a dificuldade da imitação dos objetos visuais consiste na existência do movimento e da mudança $;^{8}$ em resumo, na constante modificação da aparência das coisas visuais. De acordo com Alberti, "é impossível imitar uma coisa que não continua a manter uma

8 Apesar disso, para Alberti, a representação do movimento na pintura é de grande importância (cf. ALBERTI 1999, pp. I24-27, \$\$ 43-45). A fixação do movimento (o sopro do vento, o esvoaçar dos cabelos e das vestes) é parte integrante da imitação da natureza. 
mesma aparência” (ALBERTI I999, p. IIO, § 3I). Ainda que o objeto permaneça imóvel, basta uma mudança na posição do observador - um simples deslocamento do seu ângulo ou distância, de seu ponto de vista - para que o objeto mude sua forma, seu tamanho e seus contornos (cf. id. ibid., p. IIO, \$ 3I). Para resolver esse problema, Alberti propõe, como recurso técnico, o uso de um véu.

O véu é um tecido tênue posicionado entre o pintor e o objeto que será desenhado. Para que possa cumprir sua função, esse véu deve ter linhas horizontais e verticais, formando uma espécie de "grade" - vários quadrângulos de ângulos retos que dividem o objeto em diversas seções. Desse modo, o véu fixa a coisa vista por inteiro e cada uma de suas partes ocupa um lugar específico no interior de um dos quadrângulos do tecido. Com a ajuda desse véu, o pintor tem como referencial as linhas de cada um dos quadrados e, assim, sabe a exata posição de cada uma das partes daquilo que precisa circunscrever. "Portanto, o véu nos será de grande utilidade porque, ao ver uma coisa, ela será sempre a mesma" (id. ibid., p. IIO, § 3I). Podemos afirmar que o véu funciona como uma intersecção da pirâmide visual, pois ele se interpõe entre o olhar do artista e o objeto. Desse modo, o véu pode funcionar como uma prefiguração da própria superfície da pintura (que também é uma intersecção da pirâmide visual). $O$ artista, ao seguir a divisão dada pelo véu, é então capaz de imobilizar o objeto, delineando de maneira precisa a orla de cada uma das superfícies que o compõe. De certo modo, a circunscrição se estende para a segunda parte da pintura, a composição. Para Kossovitch, a técnica do véu e o desenho se estendem à composição, que, entretanto, é mais abrangente que a primeira parte da pintura (cf. KOSSOVITCH I999, p. 22). No entanto, antes de tratar da composição - que é, talvez, a mais importante e complexa das três partes da pintura -, trataremos da recepção de luz.

Ainda no Livro Primeiro do Da pintura, Alberti trata de algumas noções importantes para a recepção de luzes. Antes de tratar da luz diremos, brevemente, algumas coisas a respeito das cores. De acordo com Alberti, existem "quatro cores verdadeiras", cada uma derivada de um dos elementos naturais: o vermelho (cor do fogo), o azul (ar), o verde (água) e a cor cinzenta e parda (terra); as outras cores, que são espécies, são criadas a partir do acréscimo de preto (escuro) e branco (claro) (ALBERTI i999, p. 85, § 9). O preto e o branco ocupam um lugar de destaque na concepção albertiana, pois, diferentemente das quatro cores verdadeiras, o branco e o preto não são cores verdadeiras, mas somente alterações de outras cores. A recepção de luzes está intrinsecamente relacionada à utilização do preto e do branco, afinal, possi- 
A relação entre pintura e natureza em Alberti

bilitam a representação da luz e da sombra na pintura. Sendo assim, "para o pintor o branco e o preto exprimem a sombra e a claridade, sendo todas as demais cores matéria à qual ele acrescenta mais ou menos sombra ou luz" (id. ibid., p. I29, \$ 46).

Para que a pintura possa realizar-se como janela, além da perspectiva, é preciso que a luz e a sombra possam produzir uma sensação de relevo. Dito de outro modo, a "Minerva mais gorda" da pintura depende da imitação adequada da incidência de luz sobre os corpos, "nas carnes". Com isso, o volume dos objetos se evidencia. Ora, a recepção de luz é algo que diz respeito à própria natureza, e objetos de formas diferentes não recebem a luz da mesma maneira, de modo que superfícies côncavas ou convexas precisam ser sombreadas "de acordo com a posição e a qualidade da força iluminadora" (GRAYSON I999, p. 65). Para tanto, entra novamente em cena a figura do pintor como aquele que observa e aprende com a natureza; a partir de suas observações, seu engenho precisa ser capaz de transformar o aprendizado em técnica.

A imitação da natureza depende diretamente dos efeitos de luz e sombra (o claro-escuro), ou, traduzindo em termos técnicos, do bom uso de preto e branco. Caso contrário, a pintura fica limitada ao desenho, à circunscrição. Por isso, Alberti faz questão de mostrar a importância da recepção de luzes: "louvarei aquelas fisionomias que, como que esculpidas, parecem sair do quadro e criticarei aquelas em que não vejo outra arte senão a do desenho" (ALBERTI I999, p. I30, \$ 46). O domínio da luz e da sombra é necessário para que a pintura se apresente como vidro translúcido, através do qual miramos os objetos em relevo. Nesse sentido, Alberti chega até mesmo a criticar os pintores iniciantes que praticam copiando outras pinturas. Para ele, no máximo é possível treinar pintando esculturas, pois possuem um relevo natural, o que permite aprender com elas a incidência de luz sobre as formas. Mas o ideal é que o artífice aprenda os relevos dos corpos, bem como seus efeitos de luz e sombra, através da investigação da natureza.

Tratamos até aqui, de maneira geral, da primeira e terceira partes da pintura, passemos então à segunda parte: a composição. "Digo que composição é aquele processo de pintar pelo qual as partes se compõem na obra pintada" (id. ibid., p. II2, \$ 33). O elemento básico de que o pintor dispõe é a superfície; em seguida, com as superfícies, o artista compõe membros; a partir da composição dos membros, é possível dar forma aos corpos; por fim, a composição dos corpos completa a totalidade que é o objetivo máximo da pintura: a história (id. ibid.). Aqui, história deve ser entendida no sentido amplo de narração; como no exemplo da Antiguidade fornecido por Alberti, A calúnia, 
pintada por Apeles. ${ }^{9}$ Embora o artista possa dedicar-se a pintar outras coisas (retratos, por exemplo), para Alberti, a verdadeira obra do pintor é a história. Desse modo, a composição consiste fundamentalmente em uma maneira de ordenar e dispor cada uma das partes da pintura de maneira adequada e conveniente. Em suma, de acordo com Alberti, "composição é o processo de pintar pelo qual as partes das coisas vistas se ajustam na pintura" (id. ibid., p. II4, \$ 35 ). Sobre a composição seria possível dizer muitas coisas, entretanto, nos deteremos aqui na concepção de beleza tal como é desenvolvida no Da pintura.

Vimos que, para Alberti, as primeiras partes da pintura são as superfícies, das quais derivam todo o restante; o trabalho do artífice, portanto, tem início com as superfícies. É a partir da composição das superfícies que se realiza o belo na pintura. Segundo Alberti, "da composição das superfícies nasce aquela graça nos corpos a que chamamos beleza" (ibid., pp. II4-I5, § 35). Ao tratar da beleza, Alberti menciona como exemplo o rosto enrugado de uma velha, que apresenta, alternadamente, superfícies grandes e pequenas, salientes e afundadas. O modelo de beleza é o rosto jovem que, ao contrário de uma anciã, apresenta superfícies juntas, que recebem luzes amenas e suaves. Assim, na representação do corpo humano, uma composição com superfícies alternadamente côncavas e convexas são ásperas e rugosas e, portanto, feias. Enquanto uma superfície plana e uniforme, lisa e delicada, é bela (id. ibid., p. II5, § 35).

De acordo com Alberti, a composição e a representação da beleza devem ser, como tudo mais na pintura, aprendidas diretamente da natureza. "Parece-me que o caminho mais adequado e certo para quem quer atingi-las é colhê-las na própria natureza, tendo bem presente na mente de que maneira a natureza, admirável artífice das coisas, compôs bem as superfícies nos corpos belos" (id. ibid., p. II5, § 35). A composição não se aplica somente às superfícies; da mesma forma, o pintor deve ser capaz de compor com os membros e corpos, de modo que todas as partes convenham umas às outras e a obra seja um todo belo e bem-ordenado. De certo modo, a beleza deve ser aprendida pela natureza, mas o artista também deve desempenhar sua tarefa para que a pintura seja bem realizada.

Uma das tarefas do artista consiste em selecionar e eleger o belo natural, de modo que para que a beleza nasça em uma obra seja preciso à composição a arte. Alberti critica veementemente os pintores de seu tempo que con-

9 Obra perdida que inspiraria A calúnia de Apeles (I494-I495), de Botticelli. 
A relação entre pintura e natureza em Alberti

fiam somente no engenho e ignoram as lições da natureza. Sobre a questão da beleza e da função que o artista desempenha, Alberti menciona o caso exemplar de um pintor da Antiguidade. Zêuxis, ao elaborar uma pintura, não crê ser possível retirar toda a beleza de que necessita de uma só modelo; então, o pintor escolhe cinco moças e, elegendo e selecionando as partes do corpo mais belas de cada uma, compõe, assim, um belo que ultrapassa e supera a beleza individual dessas mulheres (I999, p. I43, \$56). Ora, esse exemplo mostra que a tarefa do pintor não se limita a uma imitação restrita da natureza. É preciso eleger, selecionar e compor a partir do belo natural. Alberti oferece também os exemplos de eleição nos retratos de Antígono e Péricles; este, por ter a cabeça comprida e feia, foi retratado com elmo; aquele, por ser caolho, era pintado exibindo somente o lado sadio do rosto (cf. ALBERTI i999, p. I2I, \$ 40).

Ao que parece, o resultado da intervenção do artista ultrapassa o simples belo natural e resulta em um "belo artificial". Podemos afirmar que a beleza natural dá lugar a uma "beleza eleita". Mas isso não significa que a pintura se descola da natureza; o artista apenas a "corrige" e cria a partir dela uma beleza que não existe na natureza, ou ainda, apresenta a natureza de "seu ângulo mais favorável”. Ignorar o objetivo do belo artístico pode culminar em um erro diametralmente oposto ao do pintor que confia apenas em seu próprio engenho. Nesse caso, Alberti menciona o exemplo de Demétrio, um pintor antigo que não alcançou a glória justamente por ter se preocupado tão somente com a imitação da natureza, deixando de lado o belo e o agradável (cf. id. ibid., p. I42, \$ 55). É sempre a natureza que fornece o exemplo ao pintor. O ofício da pintura parte do natural e tem na natureza sua base mais fundamental, entretanto, a arte e o engenho proporcionam a superação dos limites do natural. $O$ artífice não se limita à imitação da natureza, pelo contrário, faz parte da dignidade de seu ofício a superação de certas "inconveniências" da natureza.

Assim, a pintura ultrapassa os limites da pintura, no sentido de que o artista não está limitado à imitação servil da natureza. Seu papel na criação - mais especificamente, na composição da pintura - é determinante. Isso não quer dizer que o pintor é livre para fazer o que bem entender. Como vimos, a doutrina da pintura de Alberti apresenta preceitos bastante claros. Elogia certas práticas e critica outras. Há um conjunto de regras e normas que o artífice deve seguir. Desse modo, a pintura como doutrina sistematizada impõe aos artistas outras tantas limitações. Mas isso é uma outra história. 


\section{Conclusão}

Para Alberti, a pintura deve ser concebida como uma janela, isto é, a superfície da pintura deve ser imaginada como um vidro translúcido através do qual é possível admirar uma cena. Assim, a pintura proporciona uma representação em que os objetos aparecem em perspectiva, tal como são percebidos pela visão. Para tanto, o pintor deve ser capaz de imitar a natureza, isto é, de imitar o modo como as coisas são vistas. Inicialmente, o desenvolvimento da pintura depende da capacidade de extrair da natureza os fundamentos dessa arte, o artífice aprende os princípios (ou rudimentos) da pintura a partir da natureza. Por isso, o pintor precisa, antes de tudo, ser um atento observador.

Além da natureza, a intervenção de outros conhecimentos é crucial na redação do Da pintura. Afinal, a pintura, como arte visual, depende da compreensão de certas noções de geometria e ótica. Essas áreas do saber contribuem para o desenvolvimento de uma técnica pictórica que auxilia na realização de sua tarefa. Nesse sentido, a doutrina da pintura formulada por Alberti encerra diversos preceitos técnicos, verdadeiros ensinamentos. Uma das técnicas centrais da concepção de pintura albertiana é a perspectiva, que faz uma superfície bidimensional ganhar profundidade, tal como o mundo visível. A própria realização do conceito de pintura como janela depende de seu domínio.

Alberti divide a pintura em três partes: circunscrição, composição e recepção de luzes. Circunscrição é desenho, delineamento da orla das superfícies. Composição refere-se à conveniência entre essas superfícies, com as quais o pintor compõe membros, corpos e, finalmente, a história. A recepção de luzes trata propriamente da cor e de suas alterações devidas à incidência de luz, ou seja, dos efeitos de sombra e luz. Todas as partes da pintura são retiradas da própria natureza. Sendo assim, podemos afirmar que, na pintura, a natureza é o princípio de que parte o pintor. Seus fundamentos devem ser aprendidos diretamente da investigação da natureza.

Ainda assim, cada uma das partes se desdobra em preceitos técnicos. Por exemplo, o uso do véu no desenho, para a fixação das coisas vistas; a construção da perspectiva, que certamente, se estende à composição com suas medidas e proporções; a aplicação de preto e branco às cores para a produção de efeitos de luz e sombra. Enfim, poderíamos até mesmo conjecturar que a relação entre pintura e natureza pode ser descrita em termos de princípio, meio e fim. A natureza se mostra o princípio a partir do qual são extraídos os fundamentos da arte. A técnica aparece então como um meio para a realização de um fim. Em um primeiro momento, a finalidade parece ser a imitação da natureza. 
A relação entre pintura e natureza em Alberti

Entretanto, o artista não se limita a representar a natureza tal qual ela se apresenta. Isso fica ainda mais claro se levarmos em conta o papel criador do pintor na composição, em especial, na beleza como resultante da composição pictórica. A composição permite que o pintor, em certo sentido, ultrapasse as "limitações" da natureza. O resultado de uma pintura bem executada é o belo. A beleza, como tudo mais na pintura, deve ser retirada da natureza. No entanto, o pintor, a fim de pintar a beleza, deve compor e criar o belo que não se encontra na natureza; ele seleciona, elege e compõe a partir das belezas naturais, mas o resultado é uma beleza composta - uma beleza artificial, artística. Assim, a pintura tem como princípio a natureza, mas acaba por exceder a natureza. A função do artista não é a imitação servil. A finalidade dessa arte parece ser a representação fiel da natureza, mas que ao mesmo tempo seja capaz de sobrepujá-la de modo artificial.

\section{Referências bibliográficas}

ALBERTI, Leon Battista. Da pintura. 2. ed. Tradução Antonio da Silveira Mendonça. Campinas: Editora da Unicamp, I999. (Coleção Repertórios.)

GRAYSON, Cecil. Introdução. In: ALBERTI, Leon Battista. Da pintura. 2. ed. Tradução Antonio da Silveira Mendonça. Campinas: Editora da Unicamp, I999, pp. 35-73. (Coleção Repertórios.)

KOSSOVITGH, Léon. Apresentação. In: ALBERTI, Leon Battista. Da pintura. 2. ed. Tradução Antonio da Silveira Mendonça. Campinas: Editora da Unicamp, I999, pp. 9-33. (Coleção Repertórios.)

PANOFSKY, Erwin. Renascimento e renascimentos na arte ocidental. Tradução Fernando Neves. Lisboa: Presença, I96o.

Fabrício Behrmann Mineo - Graduando em Filosofia pela Universidade de São Paulo.

fb.mineo@gmail.com 